Tersedia online di: http://ejournal-balitbang.kkp.go.id/index.php/JP
e-mail:jurnalpari@gmail.com
JURNAL PARI
volume 4 Nomor 1 Juli 2018
p-ISSN: 2502-0730
e-ISSN : 2549-0133

\title{
FUNGSI LABEL PUNGGUNG BUKU DALAM PENJAJARAN KOLEKSI (SHELVING) DI PERPUSTAKAAN PUSAT RISET PERIKANAN
}

\author{
ARIEF GUNAWAN \\ Pusat Riset Perikanan \\ Diterima tanggal : 24 Februari 2018 Diterima setelah perbaikan : 30 Mei 2018 \\ disetujui terbit : 26 Juni 2018
}

\begin{abstract}
ABSTRAK
Label punggung buku merupakan salah satu kegiatan manajemen perpustakaan untuk memudahkan pustakawan dalam penjajaran koleksi (shelving) pada rak-rak buku atau lemari yang tersedia agar koleksi dapat ditemukan kembali dengan mudah apabila ada pemustaka yang mencari, shelving sendiri lebih mudah dilakukan dengan menggunakan klasifikasi sebagai acuan penjajaran. Di perpustakaan Pusat Riset Perikanan label punggung buku dibuat dengan menggunakan aplikasi Slims Senayan yang menyediakan menu pencetakan label. Diharapkan dengan menggunakan label punggung buku dengan tertib dapat memudahkan pustakawan dalam manajemen penempatan dan bisa menemukan kembali koleksi perpustakaan secara efektif dan efisien.
\end{abstract}

\section{Kata Kunci : label punggung buku; perpustakaan; shelving.}

\section{ABSTRACT}

The book back label is one of the library management activities to facilitate librarians in the collection alignment (shelving) on the bookshelves or cabinets available, so that the collection can be rediscovered easily when there are readers who search, shelving is easier to do by using the classification as a reference alignment. In the library of the Research Center of Fisheries the book back label is created using by Slims Senayan application that provides the label printing menu. It is hoped that using the book back label in an orderly manner facilitates librarians in placement management and can rediscover library collections effective and efficiently.

Keywords: book label backs; library; shelving 


\section{PENDAHULUAN}

Perpustakaan menurut Undang-undang RI No. 43 Tahun 2007 tentang perpustakaan adalah institusi pengelola koleksi karya tulis, karya cetak, dan/atau karya rekam secara profesional dengan sistem yang baku guna memenuhi kebutuhan pendidikan, penelitian, pelestarian, informasi dan rekreasi para pemustaka. Sedangkaan koleksi perpustakaan adalah semua informasi dalam bentuk karya tulis, karya cetak, dan/atau karya rekam dalam berbagai media yang mempunyai nilai pendidikan, yang dihimpun, diolah, dan dilayankan.

Perpustakaan Pusat Riset Perikanan (Puriskan) merupakan perpustakaan khusus lembaga pemerintah dibawah Kementerian kelautan dan Perikanan yang koleksinya lebih dikhususkan dalam bidang kelautan dan perikanan sesuai dengan kebutuhan pemustaka di lingkungannya. Pemustaka terdiri dari Peneliti, teknisi, mahasiswa, staf di lingkungan Pusat Riset Perikanan serta masyarakat yang membutuhkan informasi mengenai Kelautan dan Perikanan.

Pelabelan adalah pemasangan label pada punggung buku. Label yang ditempel pada punggung buku berisi nomor panggil. Nomor panggil adalah keterangan yang bertuliskan:

a) Nomor klasifikasi

b) Tiga huruf pertama pengarang atau nama keluarga

c) Satu huruf pertama judul

Huruf pada nomor panggil harus jelas terbaca. Nomor panggil sebaiknya ditulis dalam kertas label. Kertas label ada yang sudah jadi di pasaran. Kertas label yang digunakan di sebuah perpustakaan harus dengan ukuran yang sama. Hal ini dilakukan agar pada saat buku ada di rak posisi label sama dan terlihat lebih rapi. Apabila label tidak seukuran, pada saat dipasang/ditempel di punggung buku akan kelihatan naik turun sehingga terkesan tidak rapi.

Penjajaran koleksi (shelving) adalah kegiatan penempatan dan penyusunan kembali bahan pustaka pada rak berdasarkan nomor panggil buku, abjad judul, atau sejenisnya, termasuk dalam kegiatan ini adalah kegiatan stock opname (Peraturan Kepala Perpustakaan Nasional Republik Indonesia Nomor 11 Tahun 2015 tentang petunjuk teknis jabatan fungsional pustakawan dan angka kreditnya)

Shelving adalah kegiatan penjajaran koleksi ke dalam rak/tempat koleksi berdasarkan sistem tertentu. Kegiatan ini merupakan langkah terakhir dari proses pengolahan bahan pustaka. Tujuannya agar koleksi dapat ditemukan dengan mudah dan dapat dikenali oleh pengguna atau pustakawan.
Langkah-langkah dalam penjajaran koleksi :

1. Pengelompokan buku berdasarkan jenisnya.

Buku-buku koleksi dikelompok-kelompokkan berdasarkan jenis buku, misalnya buku referensi dikelompokkan dalam kelompok buku referensi, buku teks dikelompokkan dalam kelompok buku teks.

2. Penyusunan buku di rak

Setelah buku dikelompokkan berdasarkan jenis buku kemudian buku disusun di rak berdasarkan nomor klas dari nomor klasifikasi terkecil sampai nomor klasifikasi terbesar. Penyusunan buku dirak selain memperhatikan nomor klasifikasi, penyusunan buku juga perlu memperhatikan urutan abjad tajuk entri utama dan judul buku yang ada.

Dalam penjajaran buku ini perlu diperhatikan halhal berikut: (1) rak tidak diisi penuh untuk memudahkan penambahan dan pergeseran, (2) digunakan standar buku, (3) buku tidak disusun berlapis atau ditumpuk, (4) rak hendaknya mudah dipindahkan, (5) dan desain rak hendaknya disesuaikan agar sirkulasi udara baik (Lasa Hs, 2007:156).

Tujuan pembuatan label punggung buku agar saat memudahkan koleksi dimasukkan ke dalam rak/lemari dan bisa tersusun secara rapih berdasarkan jenis koleksi dan nomor klasifikasinya agar pada saat pencarian informasi lebih mudah dilakukan oleh pustakawan yang bertugas. Hanya dengan mengenali jenis koleksi dan nomor klasifikasi bisa langsung ditemukan informasi bahan koleksi yang dicari.

\section{METODE}

Metode yang digunakan dalam tulisan ini adalah metode deskriptif yang merupakan hasil dari penerapan aktivitas dan pekerjaan sehari-hari yang ada di perpustakaan Pusriskan yang menggambarkan pelaksanaan tugas yang dapat dilaksanakan secara efektif dan efisien.

\section{HASIL DAN BAHASAN}

Setelah bahan perpustakaan diregistrasi di buku induk, kemudian dilakukan klasifikasi berdasarkan subjek dengan menggunakan DDC (Dewey Decimal Classification), UDC (Universal Decimal Classfication) dan Library of Congress Classification serta dikelompokkan berdasarkan kelas-kelas yang ada.

Klasifikasi Desimal Dewey (Dewey Decimal Classification (DDC), juga disebut Sistem Desimal Dewey) adalah sebuah sistem klasifikasi perpustakaan yang 
diciptakan oleh Melvil Dewey (1851-1931) pada tahun 1876, dan sejak saat itu telah banyak dimodifikasi dan dikembangkan dalam duapuluh dua kali revisi yang telah terjadi hingga tahun 2004 .

Klasifikasi Dewey muncul pada sisi buku-buku koleksi perpustakaan. Klasifikasi dilakukan berdasarkan subjek, kecuali untuk karya umum dan fiksi. Kodenya ditulis atau dicetakkan ke sebuah stiker yang dilekatkan ke sisi buku atau koleksi perpustakaan tersebut. Bentuk kodenya harus lebih dari tiga digit; setelah digit ketiga akan ada sebuah tanda titik sebelum diteruskan angka berikutnya.

Untuk DDC ada sepuluh kelas utama dalam klasifikasi. Sepuluh kelas tersebut dibagi lagi kepada 10 bagian; yang lalu bisa dibagi lagi kepada 10 bagian. Sepuluh kelas utama tersebut adalah: 000 Komputer, informasi dan referensi umum 100 Filsafat dan psikologi

200 Agama

300 IImu sosial

400 Bahasa

500 Sains dan matematika

600 Teknologi

700 Kesenian dan rekreasi

800 Sastra

900 Sejarah dan geografi

UDC adalah salah satu skema klasifikasi yang digunakan di perpustakaan, bibliografi, dokumentasi dan pelayanan informasi di lebih dari 130 negara di seluruh dunia dan diterbitkan dalam lebih dari 40 bahasa. Sistem UDC merupakan penyederhanaan dan perluasan system klasifikasi DDC yang disusun oleh British Standard Institution (BSI), dibawah pengawasan International Federation for Documentation (FID). Pemikiran dadakan perluasan itu diprakarsai oleh Paul Otlet dan La Fontaine (keduanya orang Belgia) pada tahun 1895. Pada tahun 1905 terbit dalam edisi international lengkap dalam bahasa Prancis dengan judul Classification Decimal Universaille. FID, bersamasama dengan penerbit Belanda, Inggris, Perancis, Jepang dan Spanyol edisi, menjadi anggota pendiri sebuah badan baru: Konsorsium UDC (UDCC) . Konsorsium diasumsikan kepemilikan UDC pada tanggal 1 Januari 1992.

\section{Ada dua macam tabel dalam UDC:}

\section{Tabel utama}

Juga disebut 'jadwal', ini mengandung garis besar berbagai disiplin ilmu pengetahuan, diatur dalam 10 kelas dan hirarki dibagi (seperti yang dijelaskan dalam 'Struktur' di atas). Mereka diberi nomor dari 0 sampai 9.

\section{CATATAN DESKRIPSI}

0 Sains dan Pengetahuan. Organisasi. IImu Komputer. IImu Informasi. Dokumentasi. Kepustakawanan. Lembaga. Publikasi

1 Filsafat. Psikologi

2 Agama. Teologi

3 Ilmu Sosial

4 kosong

5 Matematika. IImu Pengetahuan Alam

6 Applied Sciences. Kedokteran, Teknologi

7 The Arts. Hiburan. Olahraga

8 Linguistik. Literatur

9 Geografi. Sejarah

Setiap kelas utama UDC juga berisi tabel disebut pembantu khusus (atau angka tambahan khusus), yang mengungkapkan aspek yang berulang, tetapi dalam rentang subjek yang terbatas. Ini biasanya aspek konsep yang berkaitan dengan operasi, teknik, proses, bahan, agen dll Mereka terdaftar hanya dalam bagian tertentu dari tabel utama. Nomor tambahan khusus dapat dikenali karena mereka semua mulai dengan salah satu dari tiga simbol / indikator tertentu: 0,0 (titik nol), - (hyphen) atau '(apostrof). Setiap nomor UDC awal dengan salah satu simbol-simbol ini dapat dikombinasikan dengan nomor UDC lain di daerah yang ditunjuk aplikasi.

2. Tabel tambahan umum

Tabel ini berisi tanda-tanda tambahan umum dan nomor tambahan umum.

\subsection{Tanda Bantu Umum}

Tanda-tanda (misalnya tambah, garis miring, titik dua) digunakan untuk menghubungkan dua (atau lebih) angka.

\section{CATATAN DESKRIPSI}

+ Koordinasi. Penambahan (tanda tambah). Tabel 1a

/ Ekstensi berturut-turut (tanda garis miring). Tabel 1a

: Hubungan yang sederhana (tanda titik dua). Tabel $1 b$

:: Orde-fixing (tanda titik dua ganda). Tabel 1b

[] Pengelompokan (tanda kurung siku). Tabel $1 \mathrm{~b}$

* Memperkenalkan notasi non-UDC (tanda bintang). Tabel $1 \mathrm{~h}$

\section{A / Z Langsung spesifikasi abjad. Tabel 1h}

\subsection{Nomor Bantu Umum}

Ini adalah tabel pencacahan konsep yang menunjukkan karakteristik berulang, , pembantu hanya ditambahkan pada akhir nomor subjek. Pembantu umum, berlaku di seluruh tabel utama, dan mewakili gagasan-gagasan seperti tempat, bahasa bentuk teks dan fisik dari dokumen, yang mungkin terjadi pada hampir semua subjek. 


\section{CATATAN DESKRIPSI}

$=\ldots$ Pembantu umum bahasa. Tabel $1 \mathrm{c}$

(0 ...) Pembantu umum bentuk. Tabel 1d

(1/9) Pembantu umum tempat. Tabel 1e

$(=\ldots)$ Pembantu umum keturunan manusia, pengelompokan etnis dan kebangsaan. Tabel $1 f$

“..." Pembantu umum waktu. Tabel $1 \mathrm{~g}$ membantu untuk membuat pembagian waktu misalnya: "1993-1996"

-0 ... Pembantu umum karakteristik umum: Properti, Bahan, Hubungan / Proses dan Orang. Tabel 1k.

-02 Pembantu properti umum. Tabel 1k

-03 Pembantu umum bahan. Tabel $1 \mathrm{k}$

-04 Pembantu umum hubungan, proses dan operasi. Tabel $1 \mathrm{k}$

-05 Pembantu umum orang dan karakteristik pribadi. Tabel $1 \mathrm{k}$ tabel ini diulang
Perpustakaan Puriskan sendiri menggunakan UDC sebagai acuan pengklasifikasian koleksi bahan perpustakaan baik UDC Standard Edition volume 1 dan volume 2 yang dikeluarkan British Standards Institution serta UDC versi bahasa Indonesia yang diterbitkan oleh Departemen Pertanian.

Untuk pembuatan sampai tahap pencetakan label punggung buku digunakan menu yang tersedia pada aplikasi Slims Senayan versi 7 (akasia), digunakannya aplikasi ini sesuai dengan amanat Undang-undang RI no. 43 Tahun 2007 Bab V Pasal 14 mengenai Layanan Perpustakaan ayat 3 yaitu setiap perpustakaan mengembangkan layanan perpustakaan sesuai dengan kemajuan teknologi informasi dan komunikasi.
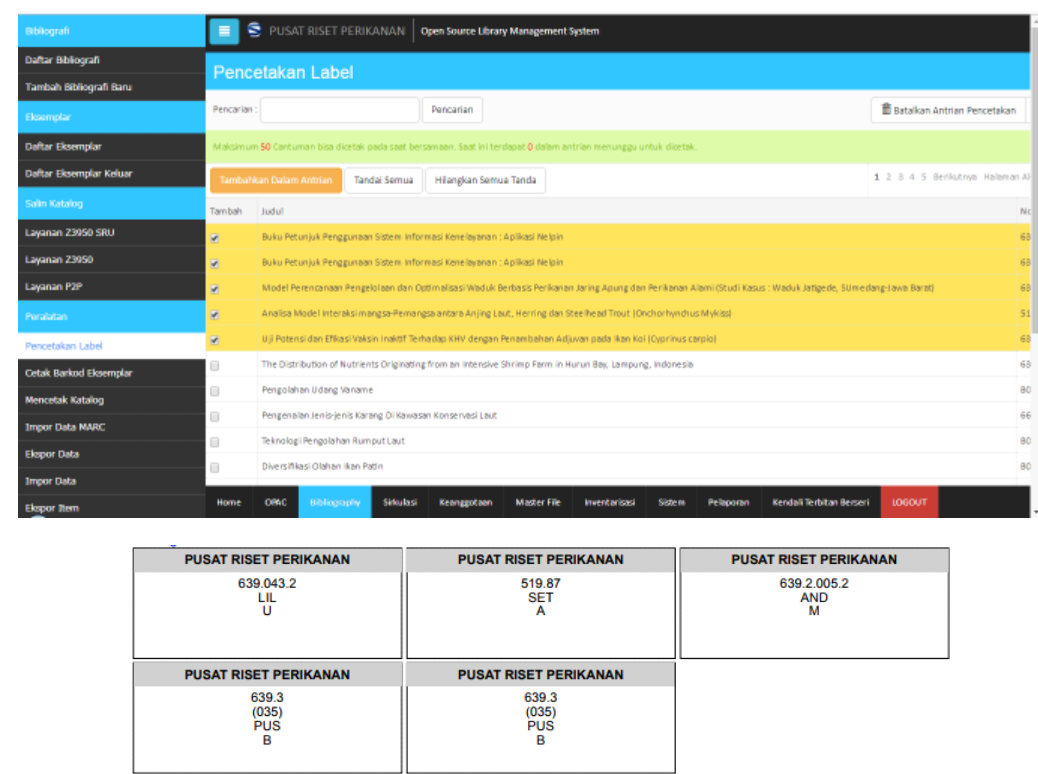

Gambar 1. Menu dan pencetakan label punggung buku pada aplikasi Slims Senayan

Setelah di print label punggung buku ditempelkan ke buku yang sesuai dengan judul dan klasifikasi yang ada seperti tampak pada gambar 2. Perpustakaan
Puriskan dalam pencetakan menggunakan kertas multi fungsi HVS 70 gram dengan penempelan menggunakan isolasi/double tape.

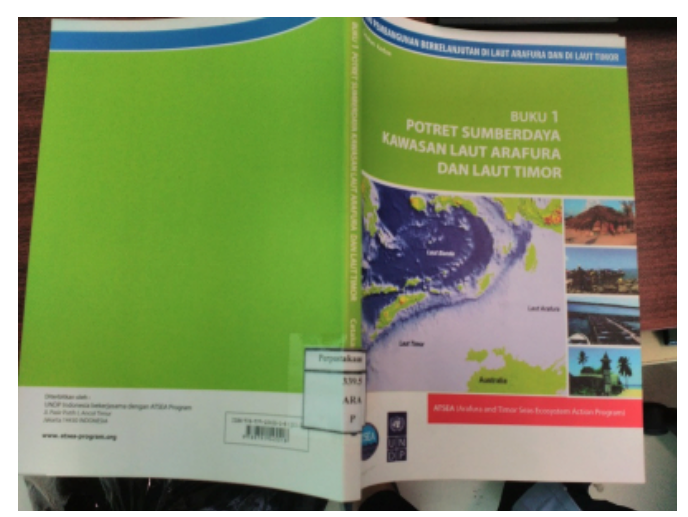

Gambar 2. Buku yang sudah ditempel label punggung buku 
Buku yang sudah ditempel label kemudian dikumpulkan sesuai klasifikasi yang ada di label dan dilakukan penjajaran (shelving) di rak-rak/lemari buku yang tersedia seperti terlihat di Gambar 3. Dengan shelving yang sesuai dengan klasifikasi ini diharapkan bisa memudahkan pustakawan dalam pencarian dan penempatan kembali koleksi perustakaan baik bahan perpustakaan yang baru maupun yang kembali setelah dipinjam.

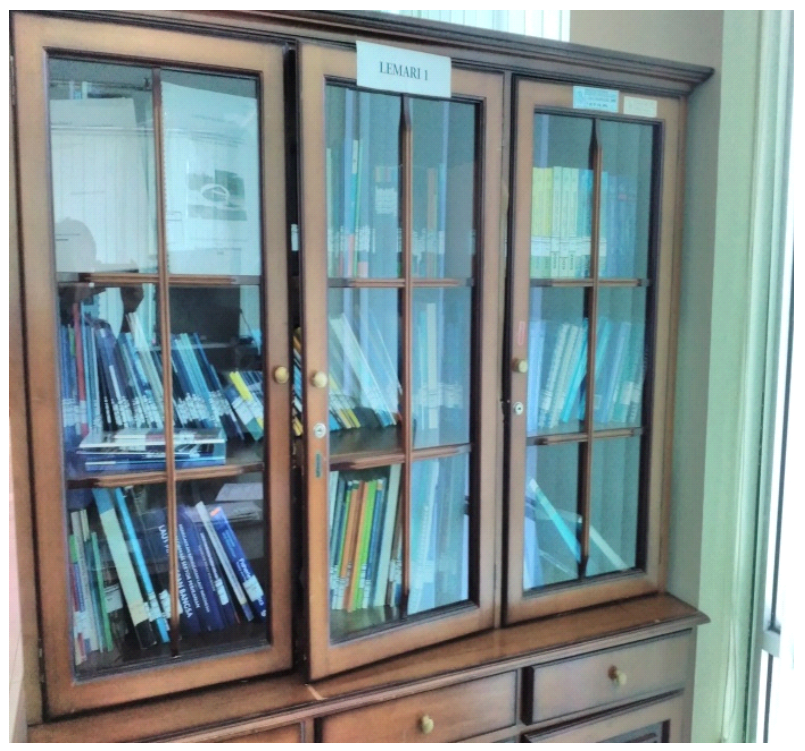

Gambar 3. Penjajaran koleksi (shelving) di lemari perpustakaan Puriskan

\section{KESIMPULAN}

Dengan memanfaatkan teknologi informasi dalam pembuatan label punggung buku ini dapat memudahkan pustakawan dalam melakukan shelving koleksi di perpustakaan Pusat Riset Perikanan baik bahan perpustakaan baru maupun setelah dipinjam oleh pemustaka, sehingga bisa tercipta manajemen perpustakan yang efisien dan efektif sesuai dengan Undang-undang Republik Indonesia No. 43 Tahun 2007 tentang Perpustakaan.

\section{DAFTAR PUSTAKA}

H.S., Lasa. 2007. Manajemen Perpustakaan Sekolah. Yogyakarta: Pinus Book Publisher
Perpustakaan Nasional Republik Indonesia. 2007. Undang-undang Republik Indonesia Nomor 43 Tentang Perpustakaan. Jakarta. Perpustakaan Nasional Republik Indonesia.

Perpustakaan Nasional Republik Indonesia. 2015. Peraturan Kepala Perpustakaan Nasional Republik Indonesia Nomor 11 Tahun 2015 tentang petunjuk teknis jabatan fungsional pustakawan dan angka kreditnya. Jakarta. Perpustakaan Nasional Republik Indonesia.

N., Wahid. 2015. Panduan Penjajaran Koleksi Perpustakaan (Shelving). Jakarta. Pusat Dokumentasi dan Informasi IImiah LIPI. 
J.Pari Vol. 4 No. 1 Juli 2018 : 